Instagraff - The influence of Web 2.0, social media, and user-created content upon graffiti

\title{
culture performed in cyber/space
}

Nicola Harding

Email: n.harding1@lancaster.ac.uk

Lancaster University Lancaster UK

(Book Chapter in 'Crime, Deviance, and Popular Culture - International and Multidisciplinary Perspectives'. Palgrave Macmillan. Release date: 15 Feb 2019).

Abstract (online only)

Instagraff, graffiti found on the social media website Instagram, examines social and technological advances that have prompted graffiti culture to appear 'mainstream'. Recognising the birth of Web 2.0 as a key turning point, this study analyses images from social media accounts of graffiti writers, relating them to the works of Goffman (The Presentation of Self in Everyday Life. University of Edinburgh and Doubleday, 1959), Burgess (Vernacular Creativity and New Media. Queensland University of Technology, Australia, 2007), and Baudrillard (The Consumer Society. Sage Publications, 1970). Its findings suggest that online representations of graffiti culture are no longer necessarily based upon sensory, deviant, risk-taking associated with urban graffiti. The use of social media by young would-be graffiti writers has created new avenues for the commercialisation of a vibrant, but deviant, subculture. Therefore, graffiti shared on social media cannot be considered a true representation of graffiti subculture, but a procession of simulacra, developing new forms of graffiti culture dislocated from graffiti's deviant origins.

Keywords

Graffiti, Social media, Web 2.0, Subculture, Visual criminology, Cultural criminology

Introduction 
During the late twentieth century, urban spaces were usually subject to some form of graffiti (Ferrell, 1995). Urban environments of today appear to be sanitised, with public spaces transformed into postmodern capitalist domains (Drzewiecka \& Nakayama, 1998). However, as this study will show, there is a space where graffiti culture is rapidly expanding; this place is the internet.

Graffiti has always been viewed as a lower working-class youth activity, with its roots in the origin of hip-hop in the 1970s (Koon-Hwee, 2001). Early subcultural theorists viewed graffiti subculture as a form of working-class resistance to the dominant discourse (Blackman, 2005; Shildrick \& MacDonald, 2006). Institutions of social control placed graffiti as an act of disorder, with broken windows theory, linking graffiti as a sign of low-level disorder to increases in actual serious crimes (Kelling \& Coles, 2011; Sampson \& Raudenbush, 2004; Wilson \& Kelling, 1982). By the mid-1990s there had been multiple graffiti moral panics and 'wars' on graffiti (Kramer, 2010; Mcauliffe, 2012). In 1972 New York City Council President Sanford Garelik called for the first 'all-out war on graffiti', a disproportional response to the issue of graffiti writing within the city (Iveson, 2010). With numerous other towns and cities in the English-speaking world using the same language of wars on graffiti since, it is the call to the general public with the language of militarism that insights and mobilises moral panics (Iveson, 2010). Iveson (2010) highlights how these 'wars' on graffiti have helped pave the way for increasing militarism within urban spaces. 'The wars on graffiti have involved the diffusion of military technologies and operational techniques into the realm of urban policy and policing' (Iveson, 2010, p. 116).

The introduction of accessible modes of communication (e.g. mobile phones) and the birth of Web 2.0 (social media and user-created content) have changed the way individuals learn and communicate about themselves (Griffiths, Light, \& Lincoln, 2012). As will be argued in this chapter, this move into the digital era has also changed the ways in which some people interact with graffiti culture. By embarking upon a digital ethnography of online space, this study collects images from social media accounts that portray their owner as a graffiti artist. It is these individuals that form online graffiti 
culture and with the images they share forming what Goffman (1959) identifies as a front stage 'presentation of self', a concept that underpins the work within this chapter. Madge and Connor's (2014) notion of cyber/space as a space that intersects the virtually real and actually real is used within this study to understand how user-created content on the internet becomes a liminal space, where young people 'try out' different identities. The analysis of images identifies the shared signs and symbols that these images use to portray graffiti culture, as such, this chapter considers the sharing of symbolic graffiti images through the writings of Baudrillard (1970), viewing cyber/space as a form of hyperreality and the images of graffiti within it a 'procession of simulacra'. Cyber/space graffiti becomes a form of vernacular creativity in itself (Burgess, 2007) - a form of graffiti culture that occasionally intersects, overlaps and is inspired by real-world graffiti, but exists without the sensory activity of real-world graffiti and the risk-taking that is associated with it.

\section{Digital Graffiti?}

Graffiti is a social phenomenon in which the social actors are nearly always invisible. Consequently, society very rarely knows the identity of graffiti artists. The main difference between graffiti in cyber/space and urban graffiti is the presence of social actors. Graffiti in cyber/space completely relies upon an individual creating an account and posting images or videos. These individual accounts place walls for graffiti to occupy whilst simultaneously building an identity for the account holder. This presentation of identity is not necessarily that individual's 'true self' but a presentation of a self.

Goffman (1959) discusses the performance that is created by a person in their everyday activities, 'expressing their identity through verbal and non-verbal messages with a goal to display the most credible image to audiences (others)' (Smith \& Sanderson, 2015, p. 343). During our day-to-day activities, we present ourselves through a front of stage performance, which is very guarded and consciously considered, and a backstage performance, where the 'self' that is portrayed is a little less planned and a little less filtered to the audience (Goffman, 1959; Smith \& Sanderson, 2015, p. 344). 
Self-presentation is a continual process of complex negotiation between these two positions, each of which may contain a multitude of presentation strategies that a person seeks to manage through a revolving process of interpreting audiences, goals and contexts.

For graffiti artists of the 1970s-1990s, the outlet for presenting themselves as graffiti artists to others outside of their immediate friendship group or ' $c r e w$ ', either as part of graffiti subculture or general population, was through the graffiti on the walls. The internet offers them the opportunity to display information about themselves as people, artists, crews to the wider graffiti subculture and the general population beyond. The key development here was the advent of social media. Social media is 'architected by design to readily support participation, peer-to-peer conversation, collaboration, and community' (Meraz, 2009, p. 682). It has given people from all walks of life the opportunity to practise enhanced self-presentation techniques, 'with the ability to engage in impression management virtually, without an audience being physically present to counteract self-presentation claims' (Smith \& Sanderson, 2015, p. 344).

Jeff Ferrell $(1995$, p. 34) stated that 'contemporary graffiti writing occurs in an urban environment increasingly defined by the segregation and control of social space'. Whilst this is mostly still the case for graffiti artists who are committed to the deviant aspects of graffiti subculture within their locality, over time different forms and spaces for graffiti have been produced. As graffiti has grown in diversity, spaces for graffiti have also diversified, with a rise in legal walls, mixed with commercial elements which invite graffiti art as part of their brand (Snyder, 2006). Through the use of graffiti within mainstream advertising, and the introduction of user-created content, graffiti is now no longer confined to the train yards and subways of urban centres. So, it is important that this research recognises and is discussed within the context of a continually evolving and diversified subculture illustrated within the writings of researchers like Ferrell $(1993,1995,1998)$ and Macdonald (2001).

It is within this evolution of graffiti culture, becoming mainstream rather than what can be considered a traditional subculture, that researchers in the post-subcultural era, such as MacDonald (2001), have 
forged the beginnings of an understanding of subcultures both on individual and structural levels. A key focus of such new understandings of subcultures is the way in which young people display identity through their subcultural practices. The works of sociologist Erving Goffman (1959) and his dramaturgical approach to the presentation of self-identity offer understanding of such subcultural display.

Within graffiti subculture, a writer cannot simply refer to himself as a graffiti writer. They are required to display themselves as 'paying their dues' before being authentic members of the graffiti subculture (Paul 107, 2003). Through time spent learning and working their way up, subcultural capital, such as recognition, respect, status and prestige, is earned (Jensen, 2006; Thornton, 1995). Sarah Thornton (1995) coined the term subcultural capital, inspired by Bourdieu's work in Distinction (1995), following his theory of cultural capital, and the work on subcultures by the Centre for Contemporary Cultural Studies. The possession of subcultural capital is the way in which members of the subculture distinguish themselves from others (Jensen, 2006; Thornton, 1995). Thornton (1995) stresses that subcultural capital is the 'characteristics, styles, knowledge and forms of practice that are rewarded with recognition, admiration, status or prestige within a subculture' (Jensen, 2006, p. 263).

In order to identify these characteristics, members of the subculture construct a symbolic binary of what it is to be 'mainstream' and what it is to be 'underground' (Jensen, 2006). Members of the subculture go through a process of differentiation, constructing an imagined other (the mainstream) 'against whom they can distinguish themselves' (Jensen, 2006, p. 263).

When presenting and managing their online identities, all the graffiti artists sampled in this study shared images that reflected significant aspects of graffiti subculture. Key recurring themes found within the images shared on Instagram and the videos posted on YouTube are the demonstration of knowledge about the history of graffiti subculture, deviancy and consumerism. The next three sections of the chapter describe and discuss the way in which these themes were represented, before considering the practical and theoretical implications for such representations of graffiti culture. 
Instagraff

This study examines how the rise in popularity of user-created content or 'social networking' on the internet has impacted graffiti subculture; specifically, through the production or reproduction of graffiti artists' identity online. The invention of the internet and the popularity of relatively inexpensive digital cameras (particularly in mobile phones) construct new avenues for artists to create and manipulate presentation of self through user-created content. The social implications of new technologies are a key rationale for using visual methods. With the research design underpinned by qualitative ethnographic methodology, the concept of the flâneur is employed as a form of data sampling.

Throughout the analysis, the internet is conceptualised as a space that can be viewed as a virtual physical space. The complexity of the relationship between what is actually real and what is virtually real can be found in the term cyber/space, as defined by Madge and Connor (2014, p. 4).

We use the term cyber/space rather than cyberspace and geographical space, to try to capture the intersecting and simultaneous nature of the virtually real and the actually real. In using cyber/space we suggest that both spaces can be concurrently entwined and experienced for a particular person in a particular instance. The use of the backslash in cyber/space is intended to be emblematic of the mutually constituted, dyadic nature of both spaces, where clear distinctions between the two spaces can become blurred. This enables cyber/space to be understood as a process as well as a site, which is brought into being through specific performances.

Information born from cyber/space and information born from the physical space of the city hold similar understandings. Understanding cyber/space in this way offers opportunity to perform a digital ethnography. Digital ethnography is a form of ethnography that uses the internet as a space for field 
work (Ardevol, 2012). Internet ethnographers focus upon the internet as a cultural artefact, using online interactions to produce field work data (Ardevol, 2012). This study combines these two approaches, by focusing upon the visual objects (photographs and video) and practices (where and how they are shared by artists); the internet is considered a cultural artefact and is the only source of data.

The development of 'Web 2.0', with HTML language capable of stimulating increasing sensory immersion and movement across virtual spaces, has enabled the internet to be considered a 'data city' (Featherstone, 1998). Within this study the researcher becomes a digital flâneur treating the internet as a virtual city, beginning with the structures that echo traditional architectural forms as they are occupied by people (social networking websites) and then using visual and multimedia 'clues' to drift in to other areas of the internet that contain images and multimedia content offering clues about graffiti subculture.

Early ethnographic studies of the internet demonstrated that 'computer-mediated interactions were socially significant and were fully loaded with meaning for the participants' (Ardevol, 2012, p. 75; Hine, 2000). Using the internet as a site of ethnographic research provides the 'conditions for studying collectives that would be practically inaccessible without the use of these technologies' (Ardevol, 2012, p. 76). The rapid growth, size of the user community and ease of access firmly locate YouTube and Instagram as symbolic 'main roads'. In the physical world Instagram and YouTube would be the spaces and places readily accessible to large sections of society, such as a local high street. These are at the forefront of internet searches and form an important part of the real and online lives of the majority of young people today.

The data collected from Instagram and YouTube resulted in 250 images and 10 videos from 35 separate users who present as part of graffiti subculture. Collected between 21 July and 21 August 2015, the hashtags \#graffiti and \#graffitiartist were used to search for images posted by graffiti artists. When an artist's social media account was identified, the ten most recent images from the account 
were collected, including a screenshot image of the account itself. Video data from YouTube was limited to the most recent video from ten separate accounts. The images and video were then coded through what was visually represented and what was represented in text through hashtags or other texts; themes were identified and framed within existing notions of graffiti subculture.

\section{Deviance}

The display of deviance was the most popular theme found in this study, with all examined accounts across both Instagram and YouTube demonstrating deviant behaviour. This included the image of the account holder's tags in public spaces, showing deviance by their existence, such as inside a train carriage and on a public bin. Including images of tags in public areas is an explicit expression of deviance from legal norms through vandalism, and risk-taking through the risk of arrest or injury (tags were often situated in 'risky' spaces such as motorway sidings, and legally 'risky' spaces such as public transport which often have CCTV and resources to arrest such as public transport police), but also a demonstration of the account holders' engagement with 'real-world' graffiti practices.

The videos consistently showed the creation of graffiti as a display of symbolic deviance: This is behaviour that appears to be deviant behaviour, such as vandalism, but may not necessarily be so. An example of this is in Madge and Connor's (2014) observations of Schofield painting his cellar wall and picturing this or filming it and posting online-the impression given that this is illegal vandalism rather than legally on private property with permission. The deviance becomes symbolic through the video, rather than actual through risk-taking. YouTube is populated by many videos that display creativity and technical ability but also prioritise messages of deviance. An example of this is the video posted by Ghost EA. In an eight-minute video, Ghost paints three pieces in three separate locations. He has titled the piece 'Forbidden Places', with the opening scene featuring a warning about CCTV (Ghost, 2015).

Ghost is viewed gesturing negatively with a pointed middle finger at the sign of authority, and then jumping over the chain fence. He then finds a wall and starts to paint. Ghost has edited the video, so 
the camera is always from his perspective, ensuring that he remains anonymous. During the process of editing, he prioritised scenes that created a deviant identity - with the selection of scenes containing enough symbolic deviance to ensure that the audience reaction is one that perceives the video to be a true example of deviant behaviour. The pieces that Ghost paints in the video are played with a hiphop sound track, with some of the lyrics indicating identification with deviance.

Videos offer a sensory experience, with music and editing to convey messages about the individuals in a way that adds to the overall message of perceived deviance. The hip-hop music lyrics add to the symbolism of the acts committed to video by Ghost, whilst linking back to graffiti cultural origins. The way the video is shot invites the viewer to take part in Ghost's act of deviance, with the music merely what he is listening to through his earphones as he jumps the fence and sprays graffiti. Ghost is not just displaying what he has done, but he invites his viewers to experience it and feel it with him.

Deviance is more subtly hinted at in images such as internet memes. The memes shared by Da5her, for example, show he recognises that he takes part in something that could get him into trouble, so he makes risk assessments of who he can trust to keep himself protected. One meme he shares has a picture of three black men huddled together in a car and says, 'this could be us... ... but you might snitch on me later so l'll go by myself'.

Through the use of memes, there is a recognition that it is the risks associated with deviance that partly make graffiti attractive. Such prominent displays of deviance indicate the desire to belong to the more deviant aspect of graffiti subculture but also show some immaturity within the subculture itself. The older, more developed accounts tend to display deviance as a necessary part of graffiti writing rather than the motivating factor. This is demonstrated through the evolution of the accounts themselves, more recent images placed less focus upon deviance and more on style and consumption, with older posts prioritising deviant behaviour. This mirrors the notion of graffiti artists 'paying their dues' through prolific tagging (Paul 107, 2003), before being taken seriously as graffiti artists by their peers. 


\section{Graffiti Subculture}

Another overarching theme discovered within the Instagram images was the recognition of the shared subcultural history of graffiti writing. This was a theme that, whilst not present in all images, was highly visible across all Instagram accounts sampled. Images referred to graffiti history in various ways.

The graffiti writers posted images of completed pieces and black book sketches in the style of their predecessors' 'wild style', including figures from popular culture in the same way graffiti writers did in the 1970s and 1980s. The images showed black sketch books with graffiti designs, mirroring both the established practice of sketching out graffiti pieces in advance and the styles of graffiti established during the 1980s. It is the use of these styles that differentiates between the images of the black book sketch pads shown in these images and more general artists displaying their sketch pads on Instagram.

Cyber/space graffiti writers also recognised the music cultural origins of hip-hop graffiti. This was demonstrated through the sharing of images of selected hip-hop artists such as Tupac Shakur and Lauren Hill on Instagram, and on YouTube by the addition of hip-hop backing music to the self-created videos. All of the videos analysed used hip-hop music, often selecting lyrics that included references to graffiti or anti-authoritarian views. The lyrics and music in 'No Jumper Cables' by Aesop Rock were used by three of the videos viewed -the song itself about graffiti and b-boying.

But you don't like our kind, do you?

Junkyard dog, hot tin roofs cradle kittens with sub-par flaws

Rappin' is my radio, graffiti is my TV

B-boys keep them windmills breezy.

'No Jumper Cables' Aesop Rock (2003)

All of the Instagram accounts examined included multiple images of trains and train yards, paying homage to the spaces that the pioneers of hip-hop graffiti occupied. Displaying images of train yards 
as the specific focus, not simply the place where graffiti has been sprayed, is a way for the account holder to demonstrate the knowledge he or she has about the subculture's origins-highlighting the significance of such spaces to where graffiti (as we know it now) began, and forging a connection between that and them.

Through these tributes, cyber/space graffiti artists demonstrate that the activities they undertake and the places in which they choose to do those activities are informed by the cultural norms and values of a wider collective called 'graffiti subculture'. The accounts of the artists who shared multiple images within this theme were older and showed a level of research into the subculture's origins; these accounts shared less images of practice and more images of actual graffiti or images symbolic within the subculture. So whilst all accounts showed at least two of these themes within their images, it was the more established accounts that shared these types of images more frequently-crafting a graffiti writer narrative.

\section{Consumption}

Consumerism is another theme present across over half of the accounts studied. The notion of 'buying' a graffiti lifestyle is a strong theme in the data collected, with accounts that use memes sharing anticonsumerist statements that critique those that 'buy' the lifestyle whilst also sharing images of 'racked' paint that will have been purchased to achieve the image. The way in which consumption is demonstrated across older and younger accounts allows us to track progression from early graffiti writer, to a writer who is more experienced and perfecting his craft, to an early graffiti entrepreneur. Older accounts had a developed base of followers and had existed for a continuous period of time with regular posting and often a developing 'brand' emerging, whilst younger accounts had far fewer followers, often under 30 followers, were sparsely or inconsistently populated with posts and often became inactive, were removed for violation of Instagram's rules or were taken down by the account holder during the time of the research. 
Graffiti entrepreneurs appear to utilise the subcultural capital gained from sharing images (their own and others') to boost their reputation and credibility. Brands started in this way have a unique insight into the cultural artefacts of graffiti. For example, in advertising, clothes line Heavy Goods display their goods with bolt cutters, gloves, a baseball cap, breathing apparatus, paint, a thick sharpie pen and Heavy Goods stickers representing slaps - a form of graffiti using premade stickers. Displaying their goods in this way, they to appeal to graffiti writers in the way only someone else from the subculture would be able to, by using their knowledge of shared subcultural meanings, artefacts and history. Advertising through social media accounts, although common among many high street retail brands, recognises the grassroots forms of communication used by graffiti writers. If the images created by graffiti entrepreneurs were placed in mainstream advertising, it would lose some communicative power and authenticity with graffiti writers themselves. An example of mainstream advertising utilising the style of grassroots movements is present in the now withdrawn Pepsi advert starring Kendall Jenner that received widespread criticism for co-opting the \#BlackLivesMatter protests held in the United States of America until it was rapidly withdrawn by Pepsi (Sanghani, 2017).

The commodification of graffiti and street art in advertising, on t-shirts, or through successful crossover into them contemporary art marketplace, has raised the profile of individual artists and the genres of graffiti and street art more generally. (Mcauliffe, 2012, p. 190)

However, the process of commercialising graffiti does not automatically remove it from its subcultural origins. Rather, the graffiti entrepreneur raises the profile of graffiti whilst remaining bound to the norms and values of the subculture. Commercial cyber/space graffiti should be viewed as an important aspect of graffiti in cyber/space, as it influences how younger writers present themselves as legitimate, authentic graffiti writers.

\section{Simulation and Simulacra}

In order to construct a believable presentation of self as a graffiti writer within cyber/space, it is crucial that the images and videos used to construct this identity show knowledge of graffiti history, 
demonstrations of deviance and appropriate consumption. Baudrillard (1970) views the consumption of goods as a new form of differentiation and stratification (Chan, 2008). Rejecting Marx's model of use-value and exchange value as an outmoded concept in the consumerist era, Baudrillard (1970) talks about capitalism no longer producing useful goods but producing 'semiotic codes and images' (Luke, 1991).

You never consume the object in itself (in its use-value); you are always manipulating objects (in the broadest sense) as signs which distinguish you either by affiliating you to your own group taken as an ideal reference or marking you off from your group by reference to a group of higher status. (Baudrillard, 1970, p. 9)

The symbolic effect of the graffiti writer's consumption can be understood as conspicuous consumption. Conspicuous consumption is the desire to 'not be identified with the poor, and a desire to be identified with the rich' (Corneo \& Jeanne, 1997, p. 56). However, graffiti writers are not simply purchasing and consuming goods to appeal to different economic classes, rather the desire to be identified with the graffiti subculture, and not to be identified with the 'mainstream'. Graffiti writers are making consumption choices that associate them with their desired group, promoting stratification through consumption choices rather than class status.

Baudrillard's (1970) writings on symbolic consumption demonstrate why graffiti writers display their purchases within the images they share, performing symbolic communication of their commitment to graffiti subculture. The graffiti writers share images of the items they are planning on buying, or wish to buy, to symbolically communicate what is graffiti subculture without even needing to engage in this consumption.

Some graffiti writers have developed into graffiti entrepreneurs, selling the products that symbolise by ownership and display a connection to graffiti subculture. Cyber/space graffiti is no longer an activity, or a product, or knowledge; it is now a 'procession of simulacra' (Luke, 1991). Image and product repetition have meant the connection to real-world graffiti has been lost. 
All visual data collected demonstrated influences of replicated graffiti culture through graffiti magazines, mainstream ad campaigns, hip-hop music videos and webpages. It is this replication of images from another image that we can understand through the writings of Baudrillard (1988). Artist Joachim Schmid structures vernacular images into arrangements of types, emphasising repetition; the overuse of everyday iconography creates cliché (Tibbs, 2012). The clichés of everyday life form nostalgia, presenting us with a fixed vision of the past, much in the same way that the images above present us with a cliché version of graffiti subculture. 'The visual cliché begets the simulacral experience. As an image accrues importance, its meaning shifts from individual to symbolic, taking on the importance of metaphor' (Tibbs, 2012, p. 4). The holiday images Schmid organised displayed themes signalling exotic travel and history (Tibbs, 2012). The images collected in this study highlight symbols of deviance and consumption. The images replicate earlier images of deviant graffiti and the graffiti lifestyle to be consumed to such an extent that they are no longer replicating an experience or act but a series of ideas that have been shared before. Graffiti images shared online create a space which does not represent the 'real' world but 'is a hyperreal: the product of an irradiating synthesis of combinatory models in a hyperspace without atmosphere' (Baudrillard, 1988, p. 366).

Tibbs explains further how images become devoid of actual emotion as they become hyperreal.

Because the tourist industry is based on capital, and capital is based on the desire of the consumer, and the consumer desires to see the place as it has been imaged so that they can image it in that same way, the place replaces itself with a clichéd idea of itself. (Tibbs, 2012, p. 5)

Similarly, cyber/space graffiti writers are consumers of graffiti culture. They portray themselves as graffiti writers, so in the same way graffiti has been 'sold' to them. Graffiti has replaced itself with a clichéd idea of itself. 
As cyber/space graffiti shortens or bypasses the processes traditionally required to gain such subcultural capital, cyber/space graffiti writers are compelled to find ways of emphasising characteristics that produce subcultural capital. In particular, the characteristic that is viewed as in direct conflict with the 'mainstream' is deviance.

Within the context of graffiti subculture, we can assume this display of abundant aerosol cans displayed in many of the collected images as a sign of skilled deviance, as previously graffiti writers would steal paint cans in order to write graffiti (Paul 107, 2003). This explains why tags and chromes were often in black and silver, as the easiest paint to steal was car paint (Paul 107, 2003). The images collected from Instagram that showed spray cans were positioned aesthetically to show both the amount of spray cans and array of colours the user possesses. This display of colours and specialist graffiti paint hints at skilled deviance, whilst also highlighting conspicuous consumption (Corneo \& Jeanne, 1997). From the pictures, it is difficult to tell if this paint has been 'racked' or if it has been purchased; but the rise in popularity of online shopping and developments in high street shop security mean that it has most likely been purchased legitimately. Ultimately, these pictures are symbolic of deviance and are firmly situated within graffiti culture. By displaying their purchased goods, these writers are able to purchase subcultural capital within graffiti culture. It is attractive to earn subcultural capital through such images-'as the wars on graffiti have escalated, so too have the subcultural rewards for those willing to engage in graffiti' (Iveson, 2010; Mcauliffe, 2012, p. 189). During cyclical moral panics about graffiti, institutions of social control announce 'wars' on graffiti in an attempt to show a zero-tolerance approach to low-level crime and disorder. In 2006 prime minister of the time, Tony Blair, was pictured 'taking up arms' in the war on graffiti by using a pressure washer to remove graffiti from a brick building; this follows on from Blair's stance of 'tough on crime, and tough on the causes of crime' (Blair, 1995; Iveson, 2010). Propaganda and public relations use militarise 'with us or against us' tactics in the war on graffiti, with New York using a multimedia campaign during the 1980s which led with the slogan 'make your mark in society, not on society' (Iveson, 2010). These wars have ensured that those who show deviance, particularly in the 
geographical areas affected, are rewarded with higher levels of respect and 'props' for the risks involved in challenging the authority of law makers.

The use of cyber/space by young would-be graffiti artists can cause conflict with others from graffiti subculture as cyber/space facilitates those with economic capital to easily exchange this for subcultural capital.

Expanding access to cyberspace has the potential of empowering new segments of the public to become fuller participants in cultural and civic life, yet we can be concerned by the ability of these electronic technologies to render invisible anyone who is not able to participate. (Jenkins, 2006 in Burgess, 2007, p. 13)

Individuals with the economic capital to buy the technology and subcultural artefacts, such as large selections of paint, are able to bypass the truly deviant risky activities traditionally associated with graffiti subculture whilst still earning subcultural capital. Those without economic capital take risks to earn subcultural capital through deviant activities. Those of lower economic status are denied the benefits of cyber/space graffiti, whilst middle- and upper-class youths are able to access subcultural capital without risking their status within 'mainstream society'. Young people manage multiple identities for different purposes online, some to gain subcultural capital while others to perform vernacular creativity. This notion of multiple identities, or more accurately multiple presentations of self, demonstrates Goffman's (1959) framework within the new context of cyber/space. 'How we socially construct our 'self' is a reflective, co-creative process that relies not only on our own careful manipulations but also on the way others understand and interpret our conveyed image' (Zavattaro, 2013, p. 512).

The co-creative process in cyber/space graffiti is one which relies upon a rudimentary understanding of graffiti culture. For a young person to 'try out' a graffiti writer identity, he has some understanding of how graffiti writers display their identity. An individual's presentation of self in cyber/space is informed by the multiple front stage presentations of others presenting themselves as graffiti writers. 
The signifiers of belonging to graffiti subculture displayed by others, such as deviance, hip-hop, wild style, racking paint and black book images, become 'processions of simulacra'. Others create similar images in order to replicate the meaning of the images that inspired this presentation of the graffiti writer self.

The key signifiers found in cyber/space graffiti images demonstrate understanding of the subculture with the more authentic and experienced social media users displaying a variety of signifiers on multiple occasions and the more inexperienced focusing upon one type of signifier alone. Users who have worked upon their presentation of self display multiple images that identify with the shared subcultural beginnings, such as images of train yards, hip-hop artists, deviance and cultural artefacts. These images combine to display a sophisticated understanding of presenting as a graffiti artist through the symbolic images that that user decides to share.

The subculture exists not simply as a residue of shared physical space but as a larger community of meaning, an exploding cultural universe of collective symbolism and style that in many ways transcends space and time. (Ferrell, 1993, 1995, 1998, p. 605)

The images themselves become less important; it is the symbolic meaning that the images convey which contributes to the presentation of self. Other artists identify the symbols contained within the images of the authentic graffiti writer and replicate them with their own similar images. When these images are grouped together, cyber/graffiti collectively reinforces the shared values and norms of graffiti subculture through a series of symbols and signs rather than experiences. It is the reduction of graffiti subculture to signs and symbols that has impacted graffiti culture since the birth of Web 2.0. Graffiti is no longer an activity to be experienced but a symbol of masculine creativity, legitimised by connections to deviance.

Young People, Social Networks and Vernacular Creativity 
The relevance of social media and engagement in subcultures facilitated by the internet extends beyond graffiti and into the everyday practices of young people and emerging adults. The activities of younger generations are linked to the invention and popularity of Web 2.0, particularly across the interests and friendship groups and networks of young people and emerging adults (Subrahmanyam et al., 2008).

Arnett (2004) uses the term 'emerging adulthood' to demonstrate the years of transition between late adolescence and young adulthood, specifically in societies with 'cultural contexts where marriage and parenthood are delayed until the late twenties or beyond' (Subrahmanyam et al., 2008, p. 422). Emerging adulthood is a 'time of exploration and instability, a self-focused age, an age of possibilities' (Arnett, 2004, p. 21), a time when emerging adults are working towards identity achievement. Despite identity formation beginning in teenage years, emerging adults were still working on identity formation in relation to vocation and careers, ethnicity and religion (Cote, 2006). Adolescents and emerging adults use social media in similar ways to build networks, maintain friendships and form identity as individuals but also as collectives.

Madge and Connor (2014) found that new mothers occupied cyber/space through networks of babyfocused message boards in similar ways to graffiti writers on Instagram. This online space allowed them to try different mothering identities that in turn influenced the kind of mother they aspired to be in the real world. For these new mothers, and for the new youth graffiti writers who benefit from the possibilities of Web 2.0, cyber/space can be considered a liminal space (Madge \& Connor, 2014). Liminality is a central element of a theoretical framework based on the notion of boundary crossings and transitions. First used within the context of anthropological study of rites of passage, liminality is one element of this wider process. (Madge \& Connor, 2014)

Cyber/space as a liminal space offers similar opportunities for graffiti writers in virtual space, as legal walls do in geographical space. Increasingly, governments and local authorities have come to compromise with graffiti writers to produce legal zones in an attempt to control illegal graffiti writing 
in urban regeneration zones; a recent example of this is the planned creation of legal walls within Bristol, an area renowned for its graffiti art (Vickers \& Morris, 2017). Legal walls and cyber/space are spaces that promote learning, growth and transition in a space that is not necessarily bound by the rules of external forces (such as criminal law or graffiti subcultures). Legal walls fall outside the rule of militaristic urban policing because they fall within the rules of local institutions of social control, such as the local council or private stakeholders. Cyber/spaces fall outside of urban policing strategies due to the difficulty of 'policing' by authorities or agents of informal social control within online spaces.

As emerging adults continue to form identities built upon vocational and career aspirations, they look to others for inspiration, advice and guidance and mentoring. By forming identities based upon ethnicity or religion, emerging adults look to others for historical and cultural connections, building their identity upon larger group identities based on shared heritage and cultural practices (Subrahmanyam et al., 2008). How adolescents and emerging adults use social media in general has implications for graffiti subculture, as there is connection between online and offline worlds and how young people present themselves (Subrahmanyam et al., 2008).

Subrahmanyam et al. (2008, p. 432) note 'although young people's offline and online worlds may be connected, they are certainly not mirror images of each other'. Emerging adults who engage as part of graffiti subculture online will not necessarily engage in public or deviant acts of graffiti in the 'real' world. This can be due to lack of access, such as disability or geographical location. However, the individual gets enjoyment out of the skill involved in graffiti and the feeling of belonging attached to contributing to something much larger and with established history and cultural practices. In this way, online graffiti can be understood as 'vernacular creativity'.

Jean Burgess $(2007$, p. 29) is the first to explain the use of the term 'vernacular creativity', using the term to 'find a way of looking at everyday cultural production that makes sense in the context of contemporary transformations in culture and new media technologies'. Vernacular creativity is the ordinary way in which we are creative in everyday life. 'Vernacular creativity, in being ordinary, is not 
elite or institutionalised; nor is it extraordinary or spectacular, but rather it is identified on the basis of its commonness' (Burgess, 2007, p. 32). The idea of what is ordinary varies amongst specific contexts and spaces, so it must be noted that vernacular is not separate to, but rather bound with, popular culture and consumption (Burgess, 2007). Graffiti can be understood as the creative activity of everyday individuals, and graffiti in cyber/space as vernacular creativity in its own right.

Subcultural capital explains the attractiveness for young people who are 'trying out' identities, to do so in liminal cyber/space. There are subcultural rewards that encourage individuals to present the identity of graffiti writer over simply sharing images of creativity alone. However, creativity is the key activity in the process of identifying as a graffiti writer. This creativity is observed in distinct ways across the visual data and many of the YouTube videos and Instagram images collected can be understood as 'vernacular creativity'. Vernacular creativity is a 'way of describing and surfacing creative practices that emerge from non-elite, specific everyday contexts' (Griffiths et al., 2012, p. 343). Griffiths et al.'s (2012) study shows young people, specifically those identifying as graffiti writers, utilising YouTube as an outlet for creativity. They describe the behind-the-scenes activities of one young person who posts on YouTube as a graffiti writer.

He would repeatedly play the video until the technique was mastered, illustrating the learning potential of technologies derided by some mainstream media as merely 'entertaining'. He would also assemble sponge mops, homemade ink and a laptop to work in the cellar of his home or wall in the garden that he had been given to practise on. (Griffiths et al., 2012, p. 347)

The process of learning and creating demonstrates the ability to earn subcultural capital without the risks traditionally associated with graffiti writing. Cyber/space graffiti has opened up the subculture to those who would have otherwise been excluded, such as those with disabilities or those who lived in rural areas restricting access to certain public spaces, especially the spaces required for deviant graffiti writing. Writers are able to produce work and share at different stages for critique, which in turn influences the skill and ability they possess in the real world. 
The process of learning via video is distinctly different to previous generations of graffiti artists. Docuyanan (2000) wrote about processes of apprenticeship, collaboration and learning occurring between older, more experienced artists and the next generation. These processes taught young writers important lessons about styles, techniques and cultural understanding (Griffiths et al., 2012). YouTube transcends the physical and geographical restrictions that would have previously restricted these interactions to a particular locality. However, the use of online videos can only convey certain aspects of graffiti subculture such as technique and style. Without the physical presence of a graffiti crew, the novice graffiti writer struggles to learn many of the subcultural aspects of graffiti writing; such as discipline, where and when to paint, and how to respect older/more talented artists.

Griffiths et al. (2012) highlight the difference between a graffiti artist in the physical world and their case study participant 'Schofield' by the lack of physical network of peers and the absence of his graffiti activities within his physically present friendship group. They suggest that this is a new way in which to practise graffiti. Previous studies have shown that notoriety gained from identifying as a graffiti artist or tagger can help navigate through certain situations such as high school (Halsey \& Young, 2002; Lachmann, 1988; Rafferty, 2002).

Schofield operated on the basis of widening his circle of creative practice and thus benefited from this in terms of the development of social capital with respect to his creativity and community involvement.(Griffiths et al., 2012, p. 348). This makes clear that, although Schofield considered himself a graffiti artist, his motivation is artistic technique and creativity rather than deviance. Griffiths et al. (2012) state this resonates with results of similar studies that examine how young people share information on social network sites (Donath, 2007; Ellison, Steinfield, \& Lampe, 2006; Griffiths et al., 2012; Joinson, 2008). Therefore, it is the specific context of a social networking website that creates these special conditions, where a young person can consider themselves a graffiti artist, engaging with the online representation of graffiti subculture, without performing the deviant acts that characterised the graffiti subculture pre-Web 2.0. It is this lack of physical participation in traditional 
graffiti subculture that has led some artists to label such writers as 'online graffiti artists' (Paul 107, 2003). This label does not deny them membership to the graffiti subculture. However, graffiti writers who have followed the more traditional route of 'paying their dues' may view online graffiti artists in a similar way to those who only paint legal walls, as graffiti tourists, rather than authentic graffiti writers (Paul 107, 2003).

Considering the ways in which earlier graffiti writers communicated as a subculture, it should not be surprising that graffiti writers use cyber/space to communicate. The birth of graffiti magazines stemmed from negative media campaigns in the 1980s by the powerful Anti-Graffiti Network (Snyder, 2006). These magazines, such as On the Go, and the International Graffiti Times or IGT (now known as The International Get Hip Times or TIGHT), were the first insight into graffiti that was not located in physical space (Snyder, 2006). Graffiti writers were inspired by punk zines, particularly the DIY aspect (Snyder, 2006).

If cyber/space can be viewed as a development in communication between graffiti writers, with early graffiti magazines as the first form of communication and collective subcultural artefacts, then it is possible to consider that the types of people engaging in cyber/space graffiti are of a similar make-up to the Zinesters identified by Stephen Duncombe in Notes from Underground (1997), 'Mostly suburban, mostly white, middle-class kids, many of whom are punk, and who express an anarchic spirit through which they relish their outsider status' (Snyder, 2006, p. 96). Online graffiti writers gain status through creative association with the subculture rather than the necessary risk-taking of real-world graffiti artists.

The formation of young people's identities in cyber/space is based upon symbols rather than experience of graffiti culture itself. These identities, when maintained in cyber/space alone, influence consumption practices of young people. However, without the sensory act of graffiti (including physical exertion, risk-taking, socialising and face-to-face interaction), the identities form shallow links to graffiti subculture, which in turn form fluid and transient identities. It is within this fickle and short- 
lived groupings based upon symbolic consumption that post-subculturalist scholars have identified as 'neo-tribes' (Bennett, 2000). Despite these more transient groupings, the desire to belong to graffiti subculture prompts young people to seek out and become part of cyber/space graffiti cultures. Therefore, when we consider if the digital age has impacted graffiti subculture, it is possible to identify a form of symbolic graffiti culture occurring in cyber/space which interacts and intersects with parts of real-life subculture. This will in turn influence graffiti practices in the real world. The links to conspicuous consumption and cyber/graffiti mean that 'real'-world graffiti subculture is resistant to cyber/space graffiti. For graffiti writers who 'paid their dues' before the birth of Web 2.0, cyber/space graffiti is too 'mainstream' to want to be identified with.

\section{Conclusion}

The process of building and maintaining graffiti subculture is a complex mix of activities of individuals within the subculture, actions of institutions of social control in response to graffiti subculture and the mass communication of graffiti subculture. To consider the impact of the digital era of communication on graffiti subculture, we must view the actions of individuals as they form presentations of themselves as graffiti artists within the wider context of graffiti's origins as a deviant subculture. Essentially, the birth of social networking and platforms promoting user-created content facilitated new forms of media and communications between graffiti writers themselves and with the wider public.

Graffiti in cyber/space is complex due to connections with real-world activities, geographies, histories and subcultural contexts. Cyber/space graffiti is simultaneously linked and dislocated from the spaces of its origin. The images shared by individuals who attempt to bridge the gap between real-world graffiti and cyber/space presentations of self demonstrate cyber/space as a liminal space. Liminal space allows for individuals to 'try out' identities, in turn influencing real-world identities. Individuals are compelled to engage with cyber/space graffiti to bypass or shorten the process of gaining 
subcultural capital, minimising actual deviance and reducing any risks towards the individual's status within 'mainstream' society.

Bypassing the process of accumulation of subcultural capital is also achieved through conspicuous consumption. Economic capital is transformed into subcultural capital as economically advantaged sections of society are able to buy/earn subcultural rewards without traditional risk factors. Conversely, those who work on presenting authentic presentations of self as graffiti writers are able to develop into subcultural entrepreneurs. They utilise their accrued subcultural capital to gain economic capital, often by selling parts of graffiti subculture to 'mainstream' audiences as well as others from the subculture.

The creation of subcultural capital online offers incentive to engage in cyber/space graffiti. But it is vernacular creativity that accounts for the process of skill-sharing and creative growth. Vernacular creativity is the term used to describe creativity in everyday life, that is, the ways in which ordinary people express themselves creatively. All profiles sampled within this study consisted of some form of vernacular creativity, building skills learned and practised in liminal cyber/space, and then used practically for real-world applications.

The process of presenting as graffiti writers online through images and video produces hundreds of thousands of graffiti images. These images reproduce key themes relating to graffiti culture: deviance, hip-hop, 'wild style' and train yards/subways. The images are individually underwhelming, yet collectively demonstrate a procession of simulacra. Similar graffiti images are shared so often that the creator of the image becomes irrelevant; the images' meaning changes the physical, creative and deviant activity into a set of symbols for deviance and disorder. The replication of graffiti images online by young people as they try out various performances of identity has not expanded graffiti subculture. Rather the over-exposure of certain types of images relating to graffiti culture has flattened the graffiti image into a series of easily identifiable symbols and stereotypes relating to urban youth deviance. 
To understand the rise in popularity of cyber/space graffiti through the notion of vernacular creativity producing subcultural capital, and economic capital, we can begin to piece together clues that point towards the impact the digital era has had on graffiti subculture. Whilst it may seem that Web 2.0 has produced a more democratic mode of media and communication, the expansion of graffiti culture in other new forms of graffiti has not been replicated here. Rather, the prolific sharing of similar images has transitioned the sensory activity of graffiti into a procession of simulacra; the image no longer holds the meaning held by the original user, but forms part of the symbols and signs that are read as graffiti subculture.

\section{References}

Aesop Rock, Blockhead and El-P. (2003). No Jumper Cables. Bazooka Tooth.

Arnett, J. (2004). Emerging Adulthood: The Winding Road from Late Teens through the Twenties. New York: Oxford University Press.

Baudrillard, J. (1970). The Consumer Society. London: Sage Publications.

Baudrillard, J. (1988). Simulacra and Simulation. In M. Poster (Ed.), Jean Baudrillard, Selected Writings (pp. 166-184). Stanford, CA: Stanford University Press.

Bennett, A. (2000). Popular Music and Youth Culture: Music Identity and Place. Basingstoke: Macmillan.

Blackman, S. (2005). Youth Subcultural Theory: A Critical Engagement with the Concept, Its Origins and Politics, from the Chicago School to Postmodernism. Journal of Youth Studies, 8(1), 1-20.

Blair, T. (1995). Leaders Speech, Brighton 1995. British Political Speech.org. Retrieved May 22, 2018, from http://www.britishpoliticalspeech.org/speech-archive.htm?speech=201

Bourdieu, P. (1995). Distinction. Oslo: Pax Forlag, AS. 
Burgess, J. (2007). Vernacular Creativity and New Media. Queensland University of Technology, Australia. Retrieved from http://eprints.qut.edu.au/16378/

Chan, M. (2008). Virtually Real and Really Virtual: Baudrillards Procession of Simulacrum and the Matrix. International Journal of Baudrillard Studies, 5(2). (Available at https://www2.ubishops.ca/baudrillardstudies/vol-5_2/v5-2-melanie-chan.html).

Corneo, G., \& Jeanne, O. (1997). Conspicuous Consumption, Snobbism and Conformism. Journal of Public Economics, 66, 55-71.

Cote, J. E. (2006). Emerging Adulthood as an Institutionalized Moratorium: Risks and Benefits to Identity Formation. In J. Arnett \& J. Tanner (Eds.), Emerging Adults in America: Coming of Age in the 21st Century (pp. 85-116). Washington, DC: American Psychological Association.

Docuyanan, F. (2000). Governing Graffiti in Contested Urban Spaces. PoLAR, 23(1), 103-121.

Donath, J. (2007). Signals in Social Supernets. Journal of Computer-Mediated Communication, 13(1), 231-251.

Drzewiecka, J. A., \& Nakayama, T. K. (1998). City Sites: Postmodern Urban Space and the Communication of Identity. Southern Communication Journal, 64(1), 20-31. Retrieved May 22, 2018, from

https://www.researchgate.net/profile/Thomas_Nakayama/publication/294285137_City_Sites/links/ 56bfe01a08ae2f498ef80f47.pdf

Ellison, N., Steinfield, C., \& Lampe, C. (2006). Spatially Bounded Online Social Networks and Social Capital: The Role of Facebook. In Annual Conference of the International Communication Association (p. 0). Retrieved from http://citeseerx.ist.psu.edu/viewdoc/download?doi=10.1.1.85.5541\&rep=rep1\&type=pdf Ferrell, J. (1993). Crimes of Style: Urban Graffiti and the Politics of Criminality. New York: Garland Publishing. 
Ferrell, J. (1995). Urban Graffiti: Crime, Control, and Resistance. Youth \& Society, 27(1), 73-92.

Ferrell, J. (1998). Freight Train Graffiti: Subculture, Crime, Dislocation. Justice Quarterly, 15(4), 587608.

Ghost, E., 2015. Forbidden Places. Published February 27, 2015. Retrieved from http://youtu.be/I7HubdMdCVM

Goffman, E. (1959). The Presentation of Self in Everyday Life. University of Edinburgh and Doubleday. Retrieved from http://www.amazon.com/dp/0385094027

Griffiths, M., Light, B., \& Lincoln, S. (2012). "Connect and Create”: Young People, YouTube and Graffiti $\begin{array}{llll}\text { Communities } & \text { (July 2015). } & \text { Retrieved }\end{array}$ http://usir.salford.ac.uk/19070/1/Connect_and_Create'_Young_People,_YouTube_and_Graffiti_Co mmunities.doc

Halsey, M., \& Young, A. (2002). The Meanings of Graffiti and Municipal Administration. Australian and New Zealand Journal of Criminology, 35, 165-186.

Iveson, K. (2010). The Wars on Graffiti and the New Military Urbanism. City, 14, 115-134.

Jensen, S. Q. (2006). Rethinking Subcultural Capital. Young, 14(3), 257-276.

Joinson, A. N. (2008). Looking At, Looking Up or Keeping Up with People? In Proceeding of the Twentysixth Annual CHI Conference on Human Factors in Computing Systems CHI 08 (p. 1027). Retrieved from http://portal.acm.org/citation.cfm?doid=1357054.1357213

Kelling, L., \& Coles, C. M. (2011). Fixing Broken Windows: Restoring Order and Reducing Crime in Our Communities by George L. Kelling and Catherine M. Coles. American Journal of Sociology, 103(2), 510512.

Koon-Hwee, K. (2001). Adolescents and Graffiti. Art Education, 54(1), 18-23. Retrieved from http://www.jstor.org/stable/3193889 
Kramer, R. (2010). Moral Panics and Urban Growth Machines: Official Reactions to Graffiti in New York City, 1990-2005. Qualitative Sociology, 33(3), 297-311.

Lachmann, R. (1988). Graffiti as Career and Ideology. American Journal of Sociology, 94(2), 229.

Luke, T. W. (1991). Power and Politics in Hyperreality: The Critical Project of Jean Baudrillard. The Social Science Journal, 28(3), 347-367.

Macdonald, N. (2001). The Graffiti Subculture. London: Palgrave Macmillan.

Macdonald, N. (2016). Something for the Boys? Exploring the Gender Dynamics of the Graffiti Subculture. In J. I. Ross \& R. Kramer (Eds.), Routledge Handbook of Graffiti and Street Art (p. 491). Oxon: $\quad$ Routledge. $\quad$ Retrieved https://books.google.co.uk/books?hl=en\&lr=\&id=kGKpCwAAQBAJ\&oi=fnd\&pg=PA183\&dq=macdona Id+masculine+creativity\&ots=a9TvAgnQzO\&sig=vFmydEFOX-

IZgCWW3_ASOni1LGM\#v=onepage\&q=macdonald masculine creativity\&f=false

Madge, C., \& Connor, H. O. (2014). Mothers in the Making? Exploring in Cyber/Space Liminality, 30(1), 83-97.

Mcauliffe, C. (2012). Graffiti or Street Art? Negotiating the Moral Geographies of the Creative City. Journal of Urban Affairs, 34(2), 189-206.

Meraz, S. (2009). Is There an Elite Hold? Traditional Media to Social Media Agenda Setting Influence in Blog Networks. Journal of Computer-Mediated Communication, 14(3), 682-707.

Paul 107. (2003). All City: The Book About Taking Space. Georgetown: ECW Press.

Rafferty, P. (2002). The Street Art Graffiti of Youth: Questioning the Normalizing Influence of Tradition. Phenomenology and Pedagogy, 9, 15-26.

Sampson, R. J., \& Raudenbush, S. W. (2004). Seeing Disorder: Neighborhood Stigma and the Social Construction of "Broken Windows". Social Psychology Quarterly, 67(4), 319-342. 
Sanghani, R. (2017). Pepsi Ad: Everything That's Wrong with THAT Kendall Jenner Video. Telegraph. Retrieved May 22, 2018, from https://www.telegraph.co.uk/women/life/pepsi-ad-everything-wrongkendall-jenner-video/

Shildrick, T., \& MacDonald, R. (2006). In Defence of Subculture: Young People, Leisure and Social Divisions. Journal of Youth Studies, 9(2), 125-140.

Smith, L. R., \& Sanderson, J. (2015). I'm Going to Instagram It! An Analysis of Athlete Self-Presentation on Instagram. Journal of Broadcasting \& Electronic Media, 59(2), 342-358. Retrieved from http://www.tandfonline.com/doi/full/10.1080/08838151.2015.1029125

Snyder, G. J. (2006). Graffiti Media and the Perpetuation of an Illegal Subculture. Crime Media Culture, 2(1), 93-101.

Subrahmanyam, K., et al. (2008). Online and Offline Social Networks: Use of Social Networking Sites by Emerging Adults. Journal of Applied Developmental Psychology, 29(6), 420-433. https://doi.org/10.1016/j.appdev.2008.07.003

Thornton, S. (1995). Club Cultures. Cambridge: Polity Press.

Tibbs, M. (2012). Snapshots, Clichés and Simulacra. In Mid-America College Art Association Conference 2012 Digital Publications. Paper 10. Retrieved from http://digitalcommons.wayne.edu/macaa2012scholarship/10

Vickers, H., \& Morris, S.. (2017). Bristol Street Artists Work with City on Legal Graffiti Walls | Art and Design | The Guardian. The Guardian. Retrieved May 22, 2018, from https://www.theguardian.com/artanddesign/2017/jan/22/bristol-street-artists-banksy-city-legalgraffiti-walls-public-art

Wilson, J., \& Kelling, G. (1982). Broken Windows: The Police and Neighborhood Safety. The Atlantic Monthly, pp. 29-38. 
Zavattaro, S. M. (2013). Expanding Goffman's Theater Metaphor to an Identity-Based View of Place Branding. Administrative Theory \& Praxis, 35(4), 510-528. Retrieved from http://mesharpe.metapress.com/openurl.asp?genre=article\&id=doi:10.2753/ATP1084-1806350403

Mike Featherstone, (2016) The FIÃçneur, the City and Virtual Public Life. Urban Studies 35 (5-6):909925

Hine, C. (2000). Virtual Ethnography. London: Sage Publications

Ardévol, E. (2012). Virtual/visual Ethnography. In Pink, S (Ed.) Advances in Visual Methodology, (pp. 74-94) London: Sage Publications.

1. Further discussion of masculinity and graffiti in the age of Web 2.0 and social networks can be found in Macdonald (2016). 